\title{
Erratum to: Panspermia, Past and Present: Astrophysical and Biophysical Conditions for the Dissemination of Life in Space
}

\author{
Paul S. Wesson
}

Published online: 17 February 2011

(C) Springer Science+Business Media B.V. 2011

\section{Erratum to: Space Sci. Rev. \\ DOI 10.1007/s11214-010-9671-x}

The received date on the published paper appears erroneously as 21 June 2010 . The actual date that the paper was received for review was 28 January 2010.

The discrepancy arose due to the fact that the paper was initially submitted directly to our Editorial board, outside our online review system http://www.editorialmanager.com/spac. Upon being uploaded to the online review system on 21 June 2010 the erroneous date was generated.

The online version of the original article can be found under doi:10.1007/s11214-010-9671-x.

P.S. Wesson $(\bowtie)$

Department of Physics and Astronomy, University of Waterloo, Waterloo, Ontario N2L 3G1, Canada

e-mail: psw.papers@yahoo.ca

P.S. Wesson

Herzberg Institute of Astrophysics, Victoria, B.C. V9E 2E7, Canada 